\title{
Taiwan and the global electronics industry
}

\author{
How did Taiwan - home to the world's largest semiconductor foundry, TSMC - become a leading player in \\ global electronics?
}

in or many years, the semiconductor industry has quietly underpinned the growth of a range of technology sectors. And during this time, the supply of integrated circuits (ICs) has been taken for granted. However, disruptions due to the coronavirus pandemic, combined with shifts in demand - the need for technology for working from home, fluctuations in the automotive sector, the deployment of $5 \mathrm{G}$ infrastructure, a push for hardware for artificial intelligence - have highlighted the importance of the IC industry in both our daily lives and the global economy ${ }^{1}$.

The IC industry is made up of a complex mix of business models and suppliers. Integrated device manufacturers (IDMs), such as Intel and Samsung, design, fabricate and sell their own ICs. But there is also a split business model - or fabless-foundry model - in which fabless design companies, such as MediaTek, design and sell ICs, but outsource their manufacture to IC foundries, such as the Taiwan Semiconductor Manufacturing Company (TSMC), who only provide manufacturing services. Both approaches remain successful, but the split approach has grown more rapidly over the last 20 years. And notably, the traditional IDM, Intel, has recently announced the launch of its own foundry services ${ }^{2}$.

Taiwan's semiconductor industry holds a leading market share in IC foundry, packaging and testing services, and is second only to the US in terms of design services and broader market share. Its success can be traced to strong government support during the early stages of the industry, a focus on developing technical skills and know-how, and being pioneers of the fabless-foundry model. In a Focus in this issue of Nature Electronics, we explore how Taiwan became a leading player in the global electronics industry.

In a Comment article, Meng-Fan Chang and colleagues highlight that back in the 1970s the Taiwanese government recognized the potential economic importance of the semiconductor industry and developed a strategy to ensure Taiwan had the technology and the engineering expertise to build a domestic supply chain. Initially, the government focused on enabling technology transfer from the US, setting up research institutes and centres, and then supporting spin-off companies. Later, as companies began to attract their own investments, the

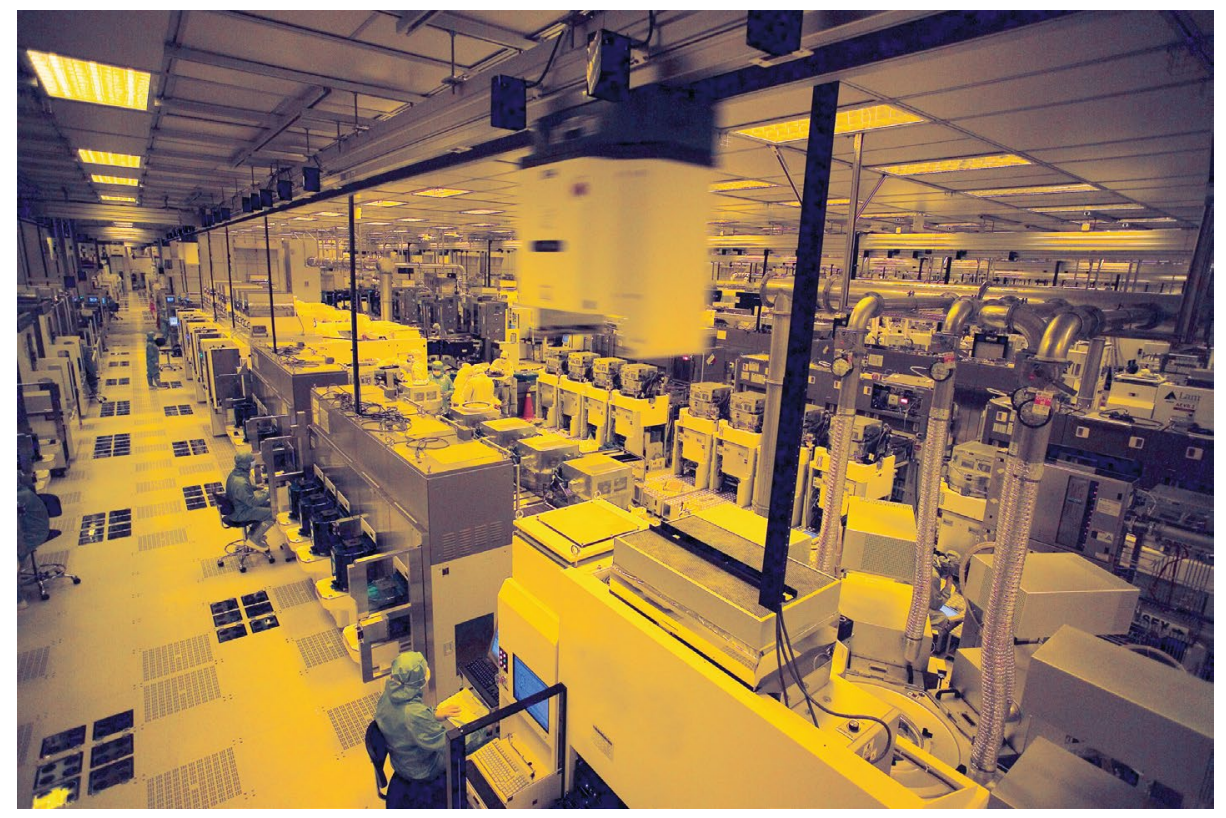

Inside a 12-inch wafer fabrication plant at TSMC. Credit: Taiwan Semiconductor Manufacturing Co., Ltd.

government focused on providing grants, subsidies and tax incentives to support academia, research institutes and industry. This has continued to this day, and support remains heavily focused on advanced technologies such as artificial intelligence.

When the semiconductor industry first emerged in Taiwan, what it could offer in terms of designs, intellectual property, and research and development capabilities was limited. But its fabrication plants performed well. In 1985, Morris Chang, while working at Taiwan's Industrial Technology Research Institute (ITRI), was asked by the government to draft a plan to create a new competitive semiconductor company. Recognizing Taiwan's strength in IC fabrication, he proposed a new, pure-play foundry business model: a company with no designs of its own, but who manufactured ICs for fabless design companies or IDMs when they needed it. In 1987, he founded TSMC, which is now the world's largest pure-play IC foundry.

In a further Comment article, Bor-Sung Liang, a senior director at MediaTek, examines how Taiwan's IC design industry has evolved over the last 50 years or so. Key to its success has been an ability to identify and supply fast-growing technology sectors, and to work with customers to bring their ideas to fruition. By developing designs and intellectual property to meet the growing demand for personal computers, and then mobile handsets and smartphones, the Taiwanese IC design industry had, by 2019 , become an industry with revenues of US $\$ 22.4$ billion.

The success of emerging technologies - from artificial intelligence to robotics to quantum computing - will depend on innovative IC designs. As Taiwan has learnt, the semiconductor industry is a costly business that requires sustained investment, and such investment will need to continue in order to supply the IC products that these emerging technologies require. But Taiwan's semiconductor industry is well placed to meet these demands - and holds lessons for those looking to join them.

Published online: 26 April 2021 https://doi.org/10.1038/s41928-021-00581-1

\footnotetext{
References

1. Fitch, A. \& Koh, E. Chips are in hot demand-and that's a problem. The Wall Street Journal https://go.nature.com $/ 3 \mathrm{a} 4 \mathrm{c} 7 \mathrm{Hm}$ (14 January 2021).

2. Intel CEO Pat Gelsinger announces 'IDM 2.0' strategy for manufacturing, innovation and product leadership. Intel News Release https://go.nature.com/3g4xsUP (23 March 2021).
} 